\title{
A Semi-Nonparametric Approach to the Demand for Money in Pakistan
}

\section{Haroon Sarwar*, Zakir Hussain ${ }^{* *}$, and Masood Sarwar ${ }^{* * *}$}

\begin{abstract}
The degree of substitutability of different monetary assets serves as a valuable source of information for Pakistan's monetary authorities in the context of money demand analysis. Barnett's (1980) concept of the micro-foundations of money demand has paved the way for a more comprehensive demand system analysis. Locally flexible functional forms are unable to estimate substitution elasticities at all data points, and thus, we use the asymptotically ideal model, which is a semi-nonparametric globally flexible functional form. Our data on income, price, and substitution elasticities show that there is less-than-perfect substitution among monetary assets. The results of Allan and Morishima elasticities show that the former are inherently biased toward showing monetary assets as complements, making Morishima a better choice. The study recommends that it is high time Pakistan's monetary authorities abandoned the simple-sum aggregation method, which assumes perfect substitution among monetary assets.
\end{abstract}

Keywords: Substitution, semi-nonparametric, globally flexible, Morishima elasticity.

\section{JEL Classification: E41.}

\section{Introduction}

The behavior of money in the context of demand systems has been well explained by Chetty (1969) in terms of the complementarity and the substitutability of different monetary assets, with the latter serving as a key guideline for many monetary authorities. Most central banks, especially in developing countries, use the simple-sum aggregation technique, in which all monetary assets are treated as perfect substitutes, which means that this aggregation methodology completely disregards the "price" of money.

\footnotetext{
* Graduate Student, Department of Economics, University of Sargodha, Pakistan.

*** Professor and Chairman, Department of Economics, University of Sargodha, Pakistan.

**** Assistant Professor, Department of Economics, University of Sargodha, Pakistan.
} 
Barnett (1980), however, raised many objections to the application of simple-sum aggregation and suggested the use of index number theory for aggregation. Earlier, his concept of the "user cost of money" in 1978 had paved new avenues in monetary aggregation theory. The Divisia-based aggregation - which is based on weighted aggregation and thus able to portray real substitution and complimentary relationships among monetary assets-appeared to be a better alternative to the simple-sum method.

Since parametric functions do not accurately approximate datagenerating functions, and thus usually restrict the substitution or complimentarity relationship among monetary assets, a better option is a semi-nonparametric function that illustrates the microeconomic properties of the consumer's money demand function. This approach translates the consumer's portfolio adjustments into substitution and complimentarity of monetary assets. In Pakistan, however, this aspect has been relatively ignored. This study aims to fill these gaps and estimates a semi-nonparametric asymptotically ideal model (AIM) for the money demand function. The AIM is a globally flexible function and allows us to easily impose regularity conditions. Using this globally flexible functional form (FFF), we estimate price, income, and substitution elasticities, the results of which could give valuable insight to Pakistan's monetary authorities for effective policy formulation.

\section{A Review of the Literature}

Since the advent of Divisia aggregates and micro-foundations, the search for an appropriate functional form for a monetary demand system has remained controversial. Initially, studies in the literature used the Cobb-Douglas and constant elasticity substitution (CES) utility functions, mainly because of their evident advantage in resolving consumer maximization problems, and because they were easy to use and interpret. Uzawa (1962), however, proved that it was incorrect to use these functional forms. To overcome this problem, the use of FFFs was introduced; Offenbacher (1979) was the first to employ an FFF, i.e., the translog. Models with FFFs provide estimates of elasticity at any point of their data and, according to Barnett, Geweke, and Wolfe (1991), do so at a high degree. FFF models thus revolutionized micro-econometrics and made it possible for neoclassical microeconomic theory to have econometric applications.

While locally FFFs were able to estimate elasticities at approximation points and gained in accuracy, they also violated global regularity. A number of empirical studies show that these models failed to 
meet the regularity conditions for optimization in large regions. Guilkey and Lovell (1980) found that the generalized Leontief and translog failed to estimate elasticities at different data points. Barnett (1983, 1985), Barnett and Lee $(1985)$, and Barnett, Lee, and Wolfe $(1985,1987)$ provided a partial solution to this problem by proposing the Minflex-Laurent model. Other examples of these types of functions are the quadratic almost-ideal demand system (AIDS) model in Banks, Blundell, and Lewbel (1997), and the general exponential form in Cooper and McLaren (1996).

While these functions were locally flexible and regular over a large region, they were still not globally regular. The problem that flexibility was achieved only at a single point, persisted. An innovation in this respect was the semi-nonparametric FFF, which had global flexibility and in which asymptotic inferences were, potentially, free from any specification errors (Serletis, 2007). Semi-nonparametric functions were able to offer an asymptotically global approximation to even to multifarious economic relationships. According to Serletis,

By global approximation one means that the flexible functional form is capable, in the limit, of approximating the unknown underlying data generating function at all points and thus of producing arbitrarily accurate elasticities at all data points (2007).

Two such semi-nonparametric functions are the Fourier FFF introduced by Gallant (1981), and the AIM introduced by Barnett and Jonas (1983), and further employed and explained by Barnett and Yue (1988). Fleissig and Swofford (1996, 1997), Fisher and Fleissig (1997), Fisher, Fleissig, and Serletis (2001), Fleissig and Serletis (2002), and Drake, Fleissig, and Swofford (2003) also use semi-nonparametric techniques and AIM specifications in their research.

Havenner and Saha (1999) estimate a number of AIM forms with multiple datasets, and list the following major advantages of using AIM specifications: (i) they are able to approximate functions over the entire range of a sample, (ii) they are globally flexible and capable of imposing regularity conditions globally rather than just locally, and (iii) there is no problem of over-fitting.

Yue (1999) uses an AIM to estimate a demand for money function for the US economy. The model guarantees asymptotic convergence to an underlying neoclassical utility function. The study finds two additional 
features of an AIM demand system for applied work. First, although there are a relatively large number of free parameters to be estimated, it is impossible to over-fit the noise in the data. Second, while neoclassical component functions cannot express movements due to measurement errors-being irregular-the AIM system simply ignores them. Yue also estimates income and price elasticities, as well as the elasticity of substitution of monetary assets. He finds that income- and cross-price elasticities suggest portfolio shifts among monetary aggregates in the 1970s and 1980s for US data. Although there are a few problems with this AIM specification, the results are encouraging for those who believe that microeconomic principles, such as utility maximization, can be applied usefully to macroeconomic problems.

Fleissig and Serletis (2002) use a Fourier series instead of AIM specifications to calculate semi-nonparametric estimates of substitution for Canadian monetary assets. The authors compute short- and long-run Morishima elasticities of substitutions for Canadian liquid assets. Their study justifies the use of a semi-nonparametric function with the argument that parametric functions fail to accurately approximate data-generating functions, and often restrict the substitutability or complementarity relationship between assets. The results show that monetary assets are substitutes for one another at all data points, both in the short- and long run.

Drake et al. (2003) apply a similar semi-nonparametric method to UK data, but while using an AIM demand system. Their study shows that the traditional Allan-Uzawa elasticity of substitution can be misleading when more than two assets are being analyzed, in which case the Morishima elasticity of substitution is more appropriate.

Drake and Fleissig (2004) conduct a cross-country study for eight EU countries for the period 1979:Q2 to 2001:Q2. The study encapsulates monetary assets by using the Divisia aggregation method, and then uses the demand system approach to estimate the elasticities of substitution for monetary assets. The purpose of the demand system approach is to derive demand share equations and elasticities of substitution from the unknown indirect utility function. The study's results show that the estimated elasticities are significantly lower than those required to form simple-sum aggregates, thus giving way to Divisia aggregation. With respect to currency substitution, the study also finds strong evidence of currency substitution in Europe. This strong currency substitution with respect to the pound sterling in Europe suggests that a European monetary union that was to include the UK would be more viable. 
Serletis and Shahmoradi (2005) focus on the demand for money in the US in the context of two globally FFFs - the Fourier and the AIM. The authors compare these two models in terms of their violation of the regularity conditions for consumer maximization, and provide a policy perspective using parameter estimates that are consistent with global regularity. The study makes a strong case for abandoning simple-sum aggregation, and also computes income- and price-elasticities and elasticity of substitution.

In Pakistan, very few studies have focused on the microeconomic foundations of the demand for money. The only relevant study is Tariq and Matthews (1997), which is confined to a comparison of simple-sum and Divisia aggregates. Although the authors do not find significant differences between the two, they argue that, if financial innovations continue, Divisia aggregates will prove far superior in the future. Since 1997, Pakistan's financial sector has undergone a significant positive change, and there is dire need to reinvestigate the case for stability as well as the micro-foundations of the money demand function for Pakistan.

\section{Data and Methodology}

Barnett (1978) introduced the idea of the "user cost of money," which became the foundation for microeconomic analysis of the monetary aggregation process. The user cost of monetary assets enables economists to investigate the representative consumer's choice set, not only over consumption goods, but also monetary services. Thus, the representative consumer's utility can be portrayed as a function of consumption goods, leisure, and monetary services:

$$
u=u(c, l, x)
$$

Here, $c$ is a vector of the services of consumption goods, $l$ is leisure time, and $x$ is a vector of the services of monetary assets. Since this is a weakly separable utility function, we focus only on the consumer's monetary problem. Following Serletis and Shahmoradi $(2005,2007)$, we assume that the consumer' monetary problem is

$$
\max f(x) \text { subject to budget constraint } p^{\prime} x=y
$$

Here, $x$ as defined above is the vector of services of monetary assets, $p$ is the corresponding vector of monetary assets' user cost, and $y$ is expenditure on monetary services. Since these monetary assets are all different, the consumer's utility function becomes 


$$
f(x)=f\left(f_{A}\left(x_{1}, x_{2}, x_{3}, x_{4}\right), f_{B}\left(x_{5}, x_{6}, x_{7}, x_{8}\right), f_{C}\left(x_{9}, x_{10}\right)\right)
$$

Here, $x_{1}$ to $x_{10}$ represent different monetary assets (see Table 1). Keeping in view the subgroups shown in the table, we calculate Divisia quantity and price indices. To design the demand system based on the given objective function above instead of using the simple-sum index, the Divisia quantity index is estimated to allow for less-than-perfect substitutability among the monetary components being analyzed.

In this study, we have used annual data on the Pakistan economy for the period 1972-2007. Our main sources are the Government of Pakistan's Handbook of Statistics on the Pakistan Economy (2005), various statistical bulletins of the State Bank of Pakistan (SBP), and data from the International Monetary Fund.

In the demand system approach, income and price elasticity, as well as the elasticity of substitution, play an important role in explaining the responsiveness of different arguments in the system. In this regard the functional form of the demand system is of critical importance. Different studies have used one of several functional forms including the Cobb-Douglas, CES, translog, AIDS, and quadratic functional form, etc., but all these are either nonflexible or only locally flexible. Only seminonparametric functions provide asymptotically global approximation for complex economic relationships. A globally FFF is capable of producing arbitrarily accurate elasticities at all data points. The two kinds of FFF include the Fourier and the AIM.

Table 1: Component Assets of Monetary Subgroups

\begin{tabular}{lcl}
\hline Subgroup & Variable & \multicolumn{1}{c}{ Asset } \\
\hline A & $X_{1}$ & Currency in circulation \\
& $X_{2}$ & Other deposits with SBP \\
& $X_{3}$ & Currency in tills of scheduled banks \\
& $X_{4}$ & Banks' deposits with SBP \\
B & $X_{5}$ & Current deposits \\
& $X_{6}$ & Call deposits \\
& $X_{7}$ & Other deposits \\
& $X_{8}$ & Savings deposits \\
C & $X_{9}$ & Time deposits \\
& $X_{10}$ & Residents' foreign currency deposits \\
\hline
\end{tabular}




\subsection{AIM Specification}

We use an AIM due to its established superiority over the Fourier. The AIM is relatively simple to use in economic analysis, while the Fourier is more appropriate to engineering and physics. Moreover, an FFF in lower orders could violate the regularity conditions (Serletis, 2007).

The general form of an AIM specification for three goods is:

$$
\begin{aligned}
& h(v)=a_{o}+\sum_{k=1}^{k} \sum_{i=1}^{3} a_{i k} v_{i}^{\lambda(k)}+\sum_{k=1}^{k} \sum_{m=1}^{k}\left[\sum_{i=1}^{3} \sum_{j=1}^{3} a_{i j k m} v_{i}^{\lambda(k)} v_{j}^{\lambda(m)}\right] \\
& +\sum_{k=1}^{k} \sum_{m=1}^{k} \sum_{g=1}^{k}\left[\sum_{i=1}^{3} \sum_{j=1}^{3} \sum_{h=1}^{3} a_{i j h k m g} v_{i}^{\lambda(k)} v_{j}^{\lambda(m)} v_{h}^{\lambda(g)}\right]
\end{aligned}
$$

Here, $\lambda(z)=2^{-2}$ for $z=\{k, m, g\}$ is the exponent set; $v_{i}, v_{j}$, and $v_{h}$ are the income-normalized prices of the three aggregates; and $a_{i k}, a_{i j k m}, \ldots$ are the parameters to be estimated. We reduce the number of parameters by deleting their diagonal terms. Similarly, to avoid extensive multiple subscripting, we re-parameterize by stacking coefficients on the same pattern as Barnett and Yue (1988).

With $n$ assets and a degree of approximation of $K$, the number of parameters to be estimated in the AIM $(K)$ model is given by the following formula:

$$
\frac{n k}{1 !}+\frac{n(n-1) k^{2}}{2 !}+\frac{n(n-1)(n-2) k^{3}}{3 !}+\ldots
$$

The AIM (1) specification used in the study after being reparameterized is

$$
\begin{aligned}
& h(v)_{k=1}=b_{o}+b_{1} v_{1}^{1 / 2}+b_{2} v_{2}^{1 / 2}+b_{3} v_{3}^{1 / 2}+b_{4} v_{1}^{1 / 2} v_{2}^{1 / 2} \\
& +b_{5} v_{1}^{1 / 2} v_{3}^{1 / 2}+b_{6} v_{2}^{1 / 2} v_{3}^{1 / 2}+b_{7} v_{1}^{1 / 2} v_{2}^{1 / 2} v_{3}^{1 / 2}
\end{aligned}
$$

Here, $v_{i}$ represents income normalized prices, $b_{i}$ is the parameter of the AIM's indirect utility function, and $k$ is the model's order of expansion. The above AIM specification is an indirect utility function; we can obtain demand share equations $s_{i}$ by applying Roy's Identity to the indirect utility function as follows: 


$$
s_{i}=\frac{v_{i}\left(\partial f_{k}(v) / \partial v_{i}\right)}{v^{\prime}\left(\partial f_{k}(v) / \partial v_{i}\right)}
$$

The share equations obtained in our three-goods case are

$$
\begin{aligned}
& s_{1}=\left(b_{1} v_{1}^{1 / 2}+b_{4} v_{1}^{1 / 2} v_{2}^{1 / 2}+b_{5} v_{1}^{1 / 2} v_{3}^{1 / 2}+b_{7} v_{1}^{1 / 2} v_{2}^{1 / 2} v_{3}^{1 / 2}\right) / D \\
& s_{2}=\left(b_{2} v_{2}^{1 / 2}+b_{4} v_{1}^{1 / 2} v_{2}^{1 / 2}+b_{6} v_{2}^{1 / 2} v_{3}^{1 / 2}+b_{7} v_{1}^{1 / 2} v_{2}^{1 / 2} v_{3}^{1 / 2}\right) / D \\
& s_{3}=\left(b_{3} v_{3}^{1 / 2}+b_{5} v_{1}^{1 / 2} v_{3}^{1 / 2}+b_{6} v_{2}^{1 / 2} v_{3}^{1 / 2}+b_{7} v_{1}^{1 / 2} v_{2}^{1 / 2} v_{3}^{1 / 2}\right) / D
\end{aligned}
$$

$D$ is the sum of the numerators in all three share equations, which we estimate using SAS 9.1 software and the model procedure, i.e., Proc Model, and applying full information maximum likelihood regression (FIML).

Having estimated the demand systems, the next step is to calculate both income and price elasticity. Both elasticities are of particular importance because they can be used to direct policy in terms of how the arguments of the underlying function affect the quantities demanded. We estimate these elasticities directly using the demand share equations through the transformation

$$
x_{i}=\frac{s_{i} m}{p_{i}} \quad i=1,2, \ldots, n
$$

Here, $s_{i}$ is the respective share, $m$ is income, and $p_{i}$ is price. Income elasticity is calculated as

$$
\eta_{i m}=\frac{m}{s_{i}} \frac{\partial s_{i}}{\partial m}
$$

Price elasticity is calculated as

$$
\eta_{i j}=\frac{p_{j}}{s_{i}} \frac{\partial s_{i}}{\partial p_{j}}-\delta_{i j}
$$

$\delta_{i j}=0$ for $i \neq j$ and 1 otherwise. If $\eta_{i j}>0$, the assets are gross substitutes; if $\eta_{i j}<0$, they are gross complements; and if $\eta_{i j}=0$, they are independent. 
The Allen elasticity of substitution between two assets is calculated as

$$
\sigma_{i j}^{a}=\eta_{i m}+\frac{\eta_{i j}}{s_{i}}
$$

The Morishima elasticity of substitution is calculated as

$$
\sigma_{i j}^{m}=s_{i}\left(\sigma_{j i}^{a}-\sigma_{i i}^{a}\right)
$$

Morishima elasticity yields better estimates because Allen elasticity can provide substitution between only two assets, and its estimation method is biased toward showing assets as complements.

\subsection{Semi-Nonparametric Estimates of Money Demand}

As mentioned earlier, parametric functions do not accurately approximate data-generating functions, and thus usually restrict the substitution or complimentarity relationship between different monetary assets. The global flexibility of our model provides an opportunity to calculate the elasticity at each point of the functions instead of only at the mean. To determine the substitutability or complimentarity of different monetary assets, we use weighted (Divisia) monetary aggregates because they allow less-than-perfect substitutability and provide a sound theoretical background. The indirect utility function is conceived keeping in view the consumer problem.

As demonstrated earlier, the AIM (1) specification of the indirect utility function used after re-parameterization is given in Equation 4; by applying Roy's Identity to the indirect utility function, we obtained share equations in the form of Equations 6 to 8. These share equations were estimated using Proc Model in SAS software, using the FIML method (see Table 2). The indirect utility function is homogeneous of degree 0 in prices and income; this was achieved by using income-normalized prices. The adding-up restriction was imposed due to the linearity of the budget constraint, and $n-1$ shares were estimated.

The nonlinear parameter estimates obtained indicate that all the parameters, barring $b_{2}$, are highly significant and the magnitude of $\mathrm{R}^{2}$ indicates the model's goodness of fit (see Table 2). The results also prove the validity of having imposed the adding-up restriction. 
Table 2: AIM Estimates (Model Procedure)

Nonlinear FIML Summary of Residual Errors

\begin{tabular}{lccccccc}
\hline Equation & DF model & DF error & SSE & MSE & Root MSE & $\mathbf{R}^{2}$ & Adj. $\mathbf{R}^{\mathbf{2}}$ \\
\hline S1 & 3 & 32 & 0.254 & 0.007 & 0.089 & 0.959 & 0.956 \\
S2 & 3 & 32 & 0.918 & 0.029 & 0.169 & 0.948 & 0.944 \\
\hline
\end{tabular}

Nonlinear FIML Parameter Estimates

\begin{tabular}{lcccc}
\hline Parameter & $\begin{array}{c}\text { Estimated } \\
\text { coefficient }\end{array}$ & $\begin{array}{c}\text { Approx. } \\
\text { standard error }\end{array}$ & $\begin{array}{c}\text { Approx. } \\
\mathbf{t} \text {-value }\end{array}$ & \begin{tabular}{l}
$\operatorname{Pr}>|\mathbf{t}|$ \\
\hline $\mathrm{b}_{1}$
\end{tabular} $\mathrm{~b}_{2}$ \\
0.213 & 0.0304 & 6.98 & $<0.0001$ \\
$\mathrm{~b}_{3}$ & -0.022 & 0.0625 & -0.36 & 0.7243 \\
$\mathrm{~b}_{4}$ & 0.809 & 0.0848 & 9.54 & $<0.0001$ \\
$\mathrm{~b}_{5}$ & 0.304 & 0.0610 & 5.01 & $<0.0001$ \\
$\mathrm{~b}_{6}$ & -0.317 & 0.0360 & -8.73 & $<0.0001$ \\
$\mathrm{~b}_{7}$ & -0.172 & 0.0170 & -10.33 & $<0.0001$ \\
Restriction & 0.018 & 0.0020 & 10.76 & $<0.0001$ \\
\hline
\end{tabular}

Source: Authors' calculations.

The nonlinear estimates provided by the AIM are not easily interpreted in terms of economic theory, and we explore their economic content through the elasticities of income, price, and, more importantly, substitution. The fit of both models is tested by plotting the actual and predicted values of both (see Figures 1 and 2), all of which fall within 95percent confidence limits. 
Figure 1: Predicted and Actual Values of Model S1

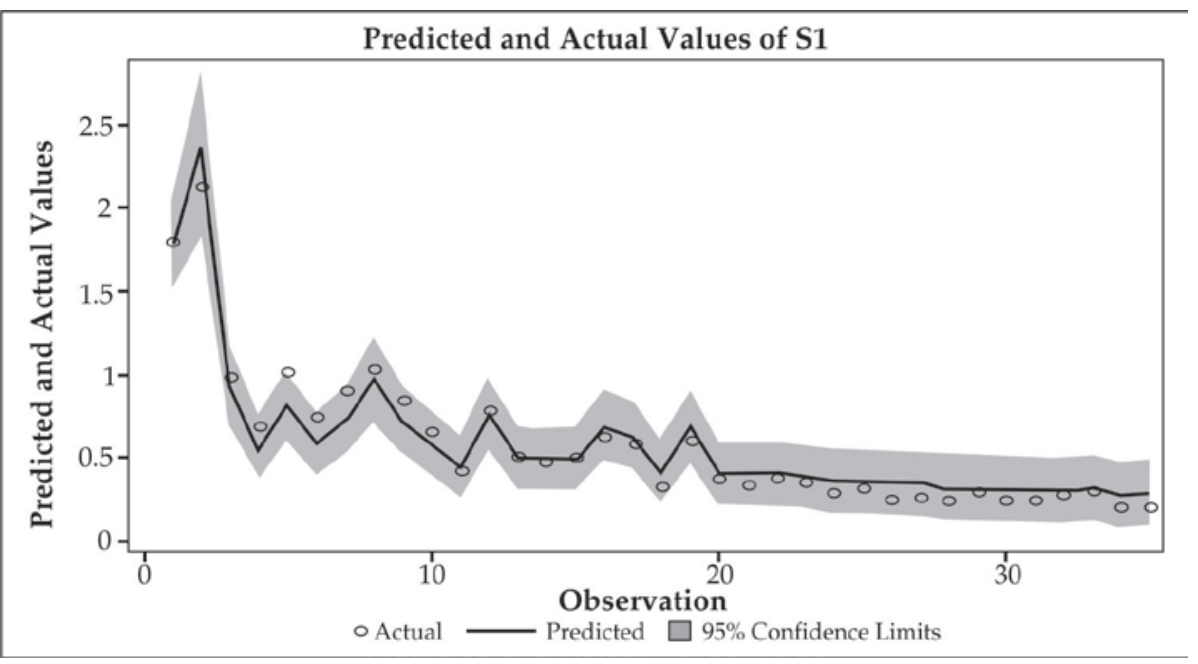

Figure 2: Predicted and Actual Values of Model S2

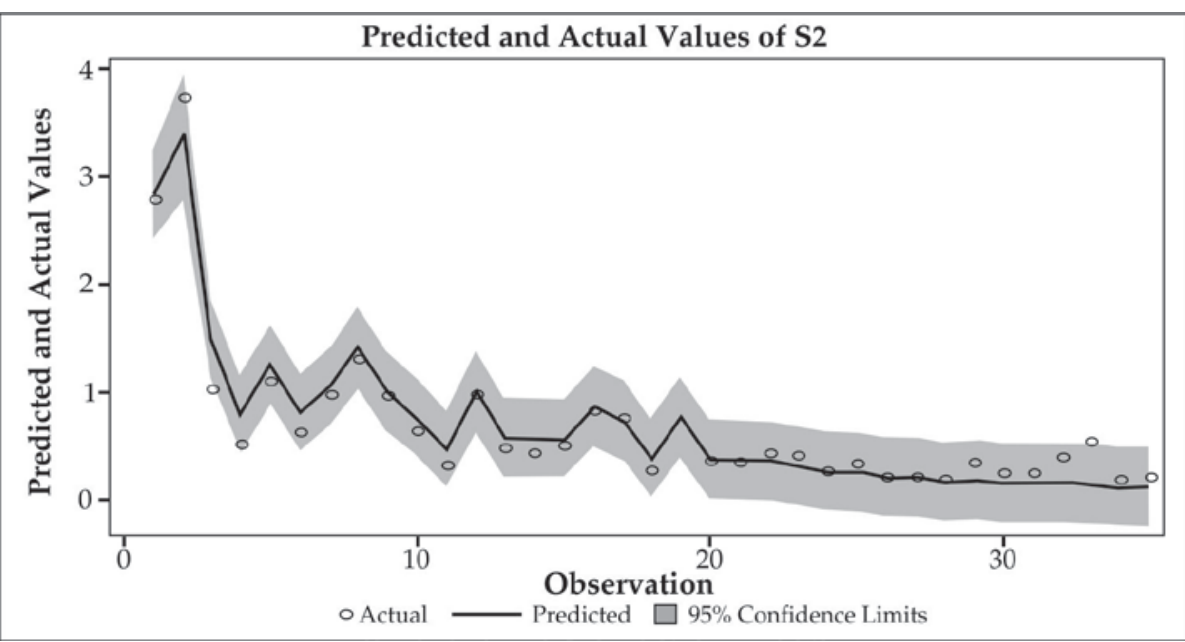

To calculate the elasticities, we compute derivatives of the demand share equations and plug these into their respective elasticity formulae. Price elasticity $\left(E_{i j}\right)$ is calculated as

$$
E_{i j}=\frac{p_{j}}{s_{i}} \frac{\partial s_{i}}{\partial p_{j}}-\delta_{i j}
$$

$\delta_{i j}=0$ for $i \neq j$ and 1 otherwise. If $E_{i j}>0$, the assets are gross substitutes; if $E_{i j}<0$, they are gross complements; and if $E_{i j}=0$, they are independent. 
The results for own- and cross-price elasticities are reported in Table 3. They show that own-price elasticities are negative, indicating a negative relationship between price and quantity of money; this is consistent with the downward-sloping demand curve relationship. An important finding is that our model satisfies the curvature requirement, i.e., that the Hessian matrix be negative semi-definite, which is clearly achieved by the negative own-price elasticities. There are a few cases of violations of curvature in the case of $E_{33}$, but they cease by increasing the AIM's degree of approximation. However, since our sample is not so large, we estimate only AIM (1).

The table's cross-price elasticities are both negative and positive. In theory, the cross-price elasticity can take any sign: a positive sign would indicate that the goods were gross substitutes, and a negative sign would indicate that they were gross complements. The dominant behavior of $E_{31}, E_{32}$, and $E_{13}$ implies that the more liquid assets-currency in circulation and time deposits-have a complementary relationship, which is borne out by the literature (see Serletis, 2007; Serletis \& Shahmoradi, 2005; Yue, 1991).

The cross-price elasticity results indicate the interesting transition of Pakistan's financial sector, which underwent a significant change in the late 1990s. In the early 1970s (after nationalization), the financial sector had borne a government footprint to the tune of 92 percent (the remaining assets were held by foreign banks). The structural transformation of the late 1990s, however, created space for the private sector. The SBP was granted more autonomy, the Pakistan Banking Council was dissolved, the Securities and Exchange Commission of Pakistan came into being, and international accounting standards were adopted. These reforms helped emancipate the banking sector, and their impact was also evident in monetary decisions as weighted average lending rates gradually came down from 15.6 percent in 1998 to 8.81 percent in June 2005.

In Table 3 , the cross-price elasticity $E_{23}$ reflects this structural change. Due to the banking sector reforms and decrease in lending rates, the sign of $E_{23}$ has been reversed. Due to the decrease in returns on longterm assets, investment moved toward the more liquid assets. 
Table 3: Own- and Cross-Price Elasticities

\begin{tabular}{|c|c|c|c|c|c|c|c|c|c|}
\hline Year & $E_{11}$ & $E_{22}$ & $E_{33}$ & $E_{12}$ & $E_{13}$ & $E_{21}$ & $E_{23}$ & $E_{31}$ & $E_{32}$ \\
\hline 1973 & -1.217 & -2.760 & 1.462 & -6.947 & -4.088 & -2.512 & -0.155 & 2.047 & 2.616 \\
\hline 974 & -1.467 & -3.507 & 2.040 & -10.067 & -5.318 & -3.569 & -0.659 & 2.807 & 3.134 \\
\hline 975 & -0.629 & -1.184 & 0.554 & -1.447 & -1.557 & -0.237 & 0.917 & 0.356 & 1.695 \\
\hline 976 & -0.608 & -0.804 & -0.157 & 0.335 & 0.003 & 0.668 & 1.102 & -0.754 & 0.155 \\
\hline 977 & -0.598 & -0.993 & 0.345 & -0.626 & -0.878 & 0.099 & 0.744 & -0.017 & 0.943 \\
\hline 978 & -0.595 & -0.787 & -0.104 & 0.257 & -0.096 & 0.572 & 0.886 & -0.624 & 0.181 \\
\hline 979 & -0.575 & -0.855 & -0.174 & -0.196 & -0.552 & 0.305 & 0.706 & -0.257 & 0.575 \\
\hline 980 & -0.561 & -0.972 & -0.608 & -1.240 & -1.472 & -0.079 & 0.545 & 0.219 & 1.207 \\
\hline 981 & -0.546 & -0.771 & -0.171 & -0.123 & -0.563 & 0.368 & 0.614 & -0.317 & 0.463 \\
\hline 1982 & -0.545 & -0.681 & -0.084 & 0.361 & -0.179 & 0.672 & 0.716 & -0.716 & 0.015 \\
\hline 983 & & & & 96 & & 07 & 30 & -1.389 & -0.877 \\
\hline 984 & -0.498 & -0.678 & 0.263 & -0.192 & -0.786 & 0.418 & 0.514 & -0.329 & 0.477 \\
\hline 985 & & -0.617 & -0.263 & 0.644 & 0.024 & 0.856 & 0.649 & -1.036 & -0.435 \\
\hline 986 & -0.549 & -0.609 & -0.283 & 0.700 & 0.039 & 0.936 & 0.678 & -1.121 & -0.515 \\
\hline 987 & -0.536 & -0.591 & -0.262 & 0.678 & -0.006 & 0.848 & 0.565 & -1.005 & -0.456 \\
\hline 1988 & -0.459 & -0.568 & 0.167 & 0.150 & -0.715 & 0.635 & 0.475 & -0.584 & 0.215 \\
\hline 1989 & -0.477 & -0.549 & 0.028 & 0.391 & -0.449 & 0.707 & 0.429 & -0.676 & -0.026 \\
\hline 1990 & -0.573 & -0.568 & -0.472 & 0.871 & 0.096 & 1.159 & 0.479 & -1.704 & -1.262 \\
\hline 1991 & -0.366 & -0.372 & 0.199 & 0.380 & -0.842 & 0.716 & 0.176 & -0.627 & -0.022 \\
\hline 1992 & -0.540 & -0.532 & -0.446 & 0.849 & 0.009 & 0.976 & 0.316 & -1.320 & -0.960 \\
\hline 993 & -0.540 & -0.525 & -0.451 & 0.922 & -0.002 & 1.020 & 0.283 & -1.426 & -1.031 \\
\hline 1994 & -0.515 & -0.493 & -0.431 & 0.882 & -0.059 & 0.906 & 0.189 & -1.192 & -0.851 \\
\hline 1995 & -0.522 & -0.488 & -0.479 & 0.879 & -0.092 & 0.887 & 0.113 & -1.228 & -0.916 \\
\hline 1996 & -0.554 & & -0.562 & 0.846 & -0.172 & 1.029 & 0.042 & -1.645 & -1.335 \\
\hline 1997 & -0.534 & -0.486 & -0.553 & 0.842 & -0.201 & 0.919 & -0.010 & -1.425 & -1.123 \\
\hline 1998 & & & -0.633 & 0.712 & -0.407 & 1.078 & -0.167 & -2.176 & -1.835 \\
\hline 1999 & -0.579 & -0.515 & -0.635 & 0.714 & -0.422 & 1.052 & -0.184 & -2.139 & -1.785 \\
\hline 2000 & -0.583 & -0.507 & -0.680 & 0.578 & -0.721 & 0.994 & -0.401 & -2.291 & -1.902 \\
\hline 2001 & -0.541 & -0.475 & -0.629 & 0.711 & -0.415 & 0.763 & -0.181 & -1.372 & -1.068 \\
\hline 2002 & -0.559 & -0.487 & -0.674 & 0.688 & -0.697 & 0.883 & -0.338 & -1.838 & -1.450 \\
\hline 2003 & -0.559 & -0.487 & -0.678 & 0.662 & -0.727 & 0.855 & -0.346 & -1.769 & -1.429 \\
\hline 2004 & -0.527 & -0.455 & -0.644 & 0.745 & -0.509 & 0.682 & -0.215 & -1.225 & -0.900 \\
\hline 2005 & -0.499 & -0.418 & -0.608 & 0.821 & -0.409 & 0.609 & -0.178 & -1.011 & -0.674 \\
\hline 2006 & -0.542 & -0.469 & -0.708 & 0.705 & -1.103 & 0.978 & -0.555 & -1.926 & -1.527 \\
\hline 2007 & -0.557 & -0.479 & -0.704 & 0.702 & -1.013 & 0.919 & -0.483 & -1.986 & -1.480 \\
\hline
\end{tabular}

Source: Authors' calculations. 
Income elasticity was calculated using the formula

$$
E_{i y}=\frac{y}{s_{i}} \frac{\partial s_{i}}{\partial y} \quad i=1,2,3
$$

$E_{i y}$ is the income elasticity of the $i$ th asset, $y$ is income, and $s_{i}$ is the $i$ th share. The results presented in Table 4 show that all the income elasticities for the three sub-aggregates are positive, implying that these monetary assets are normal goods and consumers demand more money as their incomes increase. 
Table 4: Income Elasticities of Monetary Assets

\begin{tabular}{|c|c|c|c|}
\hline Year & $\mathbf{E}_{1 \mathrm{y}}$ & $E_{2 y}$ & $E_{3 y}$ \\
\hline 1973 & 0.262 & 0.006 & 0.004 \\
\hline 1974 & 0.213 & 0.004 & 0.003 \\
\hline 1975 & 1.089 & 0.034 & 0.020 \\
\hline 1976 & 1.316 & 0.114 & 0.097 \\
\hline 1977 & 1.249 & 0.049 & 0.029 \\
\hline 1978 & 1.366 & 0.108 & 0.083 \\
\hline 1979 & 1.379 & 0.069 & 0.042 \\
\hline 1980 & 1.259 & 0.043 & 0.021 \\
\hline 1981 & 1.465 & 0.078 & 0.045 \\
\hline 1982 & 1.509 & 0.124 & 0.083 \\
\hline 1983 & 1.132 & 0.239 & 0.252 \\
\hline 1984 & 1.570 & 0.080 & 0.040 \\
\hline 1985 & 1.415 & 0.184 & 0.148 \\
\hline 1986 & 1.397 & 0.192 & 0.158 \\
\hline 1987 & 1.448 & 0.190 & 0.148 \\
\hline 1988 & 1.706 & 0.104 & 0.051 \\
\hline 1989 & 1.681 & 0.128 & 0.068 \\
\hline 1990 & 1.079 & 0.278 & 0.298 \\
\hline 1991 & 1.908 & 0.126 & 0.053 \\
\hline 1992 & 1.189 & 0.276 & 0.273 \\
\hline 1993 & 1.197 & 0.281 & 0.276 \\
\hline 1994 & 1.279 & 0.279 & 0.258 \\
\hline 1995 & 1.187 & 0.298 & 0.292 \\
\hline 1996 & 0.938 & 0.314 & 0.343 \\
\hline 1997 & 1.008 & 0.316 & 0.335 \\
\hline 1998 & 0.706 & 0.309 & 0.339 \\
\hline 1999 & 0.716 & 0.310 & 0.339 \\
\hline 2000 & 0.582 & 0.291 & 0.307 \\
\hline 2001 & 0.824 & 0.318 & 0.340 \\
\hline 2002 & 0.662 & 0.302 & 0.318 \\
\hline 2003 & 0.638 & 0.298 & 0.313 \\
\hline 2004 & 0.833 & 0.319 & 0.336 \\
\hline 2005 & 1.019 & 0.330 & 0.338 \\
\hline 2006 & 0.579 & 0.285 & 0.292 \\
\hline 2007 & 0.594 & 0.289 & 0.298 \\
\hline
\end{tabular}

Source: Authors' calculations. 
This finding is consistent with previous studies (Akhtar, 1994; Khan, 1994), and implies that, as per capita income rises, the demand for money increases since the income elasticity is positive. Over time, the decrease in income elasticity of reserve money indicates that, with financial developments such as debit and credit cards, and ATMs, etc., the extent of preference for cash has diminished. On the other hand, the increasing magnitude of income elasticities for narrow and broad aggregates shows that the demand for these assets rises as incomes increase (see Table 4).

Next, we estimate the elasticity of substitution, which measures the degree of substitutability of financial assets. These estimates are of critical importance because they are directly related to our main hypothesis concerning the perfect substitutability of monetary assets. The calculation of elasticities of substitution over time using a globally flexible function enables us capture the consumer's portfolio adjustments with changes in the user cost of financial assets. Two options are available in this regard: Allen elasticity of substitution (AE) and Morishima elasticity of substitution (ME). Blackorby and Russell $(1981,1989)$ argue that Allen elasticity does not provide correct estimates if there are more than two assets. In this situation, Morishima elasticity provides robust and unambiguous results.

The Allen elasticity of substitution is calculated using the formula

$$
A E_{i j}=E_{i y}+\frac{E_{i j}}{S_{i}}
$$

$E_{i y}$ is the income elasticity of the $i$ th asset and $E_{i j}$ is the cross-price elasticity of demand for asset $i$ due to changes in the price of asset $j$. The results for the Allen elasticities of substitution are presented in Table 5. 
Table 5: Allen Elasticities of Substitution

\begin{tabular}{lcccccc}
\hline Year & $\mathbf{A E}_{11}$ & $\mathbf{A E}_{22}$ & $\mathbf{A E}_{33}$ & $\mathbf{A E}_{12}$ & $\mathbf{A E}_{32}$ & $\mathbf{A E}_{31}$ \\
\hline 1973 & -0.414 & -0.984 & 0.519 & -2.230 & 0.943 & 1.140 \\
1974 & -0.474 & -0.935 & 0.539 & -2.484 & 0.843 & 1.317 \\
1975 & 0.449 & -1.113 & 0.549 & -0.313 & 1.662 & 0.382 \\
1976 & 0.432 & -1.413 & -0.205 & 1.953 & 0.392 & -0.999 \\
1977 & 0.664 & -0.846 & 0.338 & 0.685 & 0.879 & 0.012 \\
1978 & 0.565 & -1.121 & -0.083 & 1.767 & 0.365 & -0.757 \\
1979 & 0.741 & -0.801 & 0.218 & 1.179 & 0.627 & -0.243 \\
1980 & 0.714 & -0.695 & 0.474 & 0.317 & 0.938 & 0.234 \\
1981 & 0.816 & -0.711 & 0.218 & 1.339 & 0.518 & -0.331 \\
1982 & 0.681 & -0.925 & -0.045 & 2.066 & 0.107 & -1.004 \\
1983 & -0.225 & -1.678 & -1.033 & 3.267 & -2.438 & -2.953 \\
1984 & 0.936 & -0.608 & 0.300 & 1.375 & 0.525 & -0.378 \\
1985 & 0.334 & -1.087 & -0.398 & 2.739 & -0.747 & -1.886 \\
1986 & 0.242 & -1.193 & -0.473 & 2.989 & -1.013 & -2.199 \\
1987 & 0.375 & -0.968 & -0.358 & 2.777 & -0.746 & -1.862 \\
1988 & 0.981 & -0.577 & 0.248 & 1.886 & 0.309 & -0.869 \\
1989 & 0.864 & -0.589 & 0.103 & 2.192 & 0.034 & -1.089 \\
1990 & -0.654 & -1.767 & -1.432 & 4.209 & -4.239 & -4.857 \\
1991 & 1.310 & -0.257 & 0.241 & 2.301 & 0.029 & -0.971 \\
1992 & -0.259 & -1.164 & -0.896 & 3.486 & -2.324 & -3.266 \\
1993 & -0.391 & -1.187 & -0.986 & 3.776 & -2.608 & -3.916 \\
1994 & -0.076 & -0.849 & -0.690 & 3.298 & -1.689 & -2.880 \\
1995 & -0.282 & -0.879 & -0.820 & 3.305 & -1.916 & -3.166 \\
1996 & -0.939 & -1.474 & -1.602 & 3.902 & -4.336 & -5.230 \\
1997 & -0.679 & -1.095 & -1.242 & 3.455 & -2.927 & -4.167 \\
1998 & -1.604 & -2.106 & -2.760 & 4.007 & -8.164 & -8.261 \\
1999 & -1.539 & -1.988 & -2.684 & 3.898 & -7.624 & -7.994 \\
2000 & -1.795 & -2.206 & -3.196 & 3.427 & -9.056 & -9.029 \\
2001 & -0.985 & -1.035 & -1.452 & 2.850 & -2.704 & -4.252 \\
2002 & -1.649 & -1.622 & -2.372 & 3.385 & -5.415 & -7.275 \\
2003 & -1.657 & -1.631 & -2.334 & 3.261 & -5.349 & -6.950 \\
2004 & -1.029 & -0.822 & -1.254 & 2.701 & -1.919 & -3.994 \\
2005 & -0.610 & -0.430 & -0.771 & 2.513 & -0.887 & -2.959 \\
2006 & -2.078 & -2.064 & -2.794 & 4.109 & -7.353 & -9.146 \\
2007 & -2.091 & -1.849 & -2.721 & 3.728 & -6.311 & -9.277 \\
\hline
\end{tabular}

Source: Authors' calculations. 
The dominant pattern assumed by the estimates of Allen ownsubstitution elasticity is negative, as expected. But the remaining three Allen elasticities are not deemed reliable due to their inherent drawback as pointed out by Blackorby and Russell (1981, 1989). To overcome this, we use Morishima elasticity, which is calculated as

$$
M E_{i j}=s_{i}\left(A E_{j i}-A E_{i i}\right)
$$

Here, $s_{i}$ is the share of the $i$ th asset. Estimates for the Morishima elasticities of substitution are shown in Table 6 and Figures 3 to 5. 
Table 6: Morishima Elasticities of Substitution

\begin{tabular}{lcccccc}
\hline Year & $\mathbf{M E}_{12}$ & $\mathbf{M E}_{21}$ & $\mathbf{M E}_{13}$ & $\mathbf{M E}_{31}$ & $\mathbf{M E}_{23}$ & $\mathbf{M E}_{32}$ \\
\hline 1973 & -1.757 & -3.473 & 2.799 & -4.819 & 5.372 & -1.613 \\
1974 & -2.549 & -5.781 & 3.824 & -6.559 & 6.637 & -2.694 \\
1975 & -0.645 & 0.825 & -0.066 & -0.993 & 2.864 & 0.377 \\
1976 & 0.449 & 1.771 & -0.985 & 0.796 & 0.949 & 1.268 \\
1977 & -0.528 & 1.697 & -0.665 & 0.140 & 1.914 & 0.421 \\
1978 & 0.233 & 1.849 & -0.982 & 0.818 & 0.952 & 1.006 \\
1979 & -0.299 & 1.946 & -0.886 & 0.588 & 1.403 & 0.559 \\
1980 & -0.771 & 1.332 & -0.495 & -0.418 & 2.151 & -0.034 \\
1981 & -0.254 & 2.005 & -0.968 & 0.658 & 1.201 & 0.476 \\
1982 & 0.305 & 1.940 & -1.110 & 0.836 & 0.669 & 0.826 \\
1983 & 1.208 & 1.611 & -1.182 & 0.878 & -0.248 & 1.139 \\
1984 & -0.255 & 1.952 & -1.033 & 0.496 & 1.115 & 0.292 \\
1985 & 0.779 & 1.859 & -1.131 & 0.899 & 0.165 & 0.930 \\
1986 & 0.912 & 1.839 & -1.160 & 0.877 & 0.079 & 0.976 \\
1987 & 0.755 & 1.910 & -1.119 & 0.928 & 0.114 & 0.848 \\
1988 & 0.078 & 2.054 & -1.174 & 0.518 & 0.739 & 0.353 \\
1989 & 0.277 & 2.127 & -1.141 & 0.822 & 0.477 & 0.449 \\
1990 & 1.468 & 1.663 & -1.389 & 0.781 & -0.688 & 0.946 \\
1991 & -0.009 & 2.479 & -1.397 & 0.927 & 0.278 & 0.054 \\
1992 & 1.175 & 1.719 & -1.122 & 0.806 & -0.429 & 0.763 \\
1993 & 1.248 & 1.775 & -1.199 & 0.778 & -0.508 & 0.736 \\
1994 & 1.042 & 1.812 & -1.065 & 0.837 & -0.367 & 0.631 \\
1995 & 1.094 & 1.736 & -1.025 & 0.771 & -0.430 & 0.594 \\
1996 & 1.399 & 1.534 & -1.267 & 0.561 & -0.817 & 0.595 \\
1997 & 1.235 & 1.565 & -1.104 & 0.588 & -0.631 & 0.536 \\
1998 & 1.562 & 1.319 & -1.684 & 0.301 & -1.308 & 0.460 \\
1999 & 1.527 & 1.319 & -1.657 & 0.292 & -1.264 & 0.445 \\
2000 & 1.506 & 1.144 & -1.776 & 0.013 & -1.391 & 0.276 \\
2001 & 1.152 & 1.363 & -0.976 & 0.385 & -0.586 & 0.441 \\
2002 & 1.356 & 1.267 & -1.362 & 0.063 & -0.959 & 0.332 \\
2003 & 1.331 & 1.234 & -1.289 & 0.033 & -0.938 & 0.328 \\
2004 & 1.063 & 1.405 & -0.839 & 0.336 & -0.438 & 0.422 \\
2005 & 0.898 & 1.618 & -0.720 & 0.572 & -0.252 & 0.426 \\
2006 & 1.459 & 1.233 & -1.442 & -0.328 & -1.057 & 0.152 \\
2007 & 1.413 & 1.249 & -1.490 & -0.241 & -0.999 & 0.218 \\
\hline & & & & & & \\
& & & & &
\end{tabular}

Source: Authors' calculations. 
Figure 3: Morishima Elasticity ME32

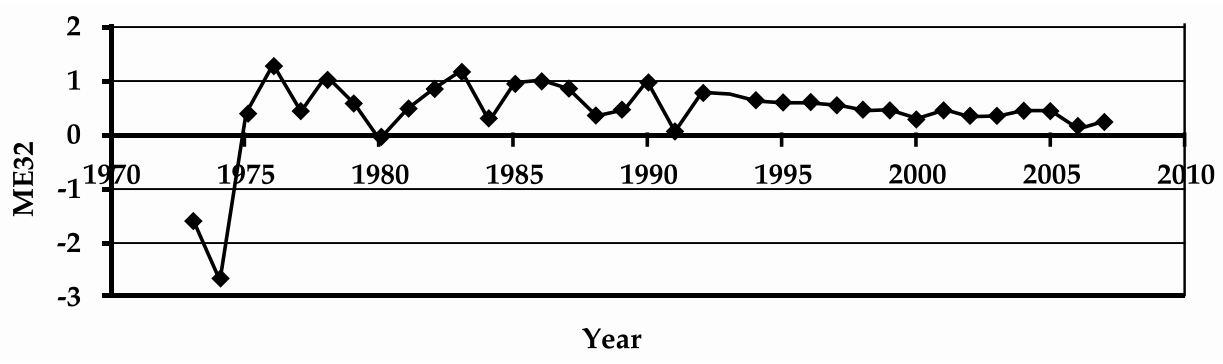

Figure 4: Morishima Elasticity ME23

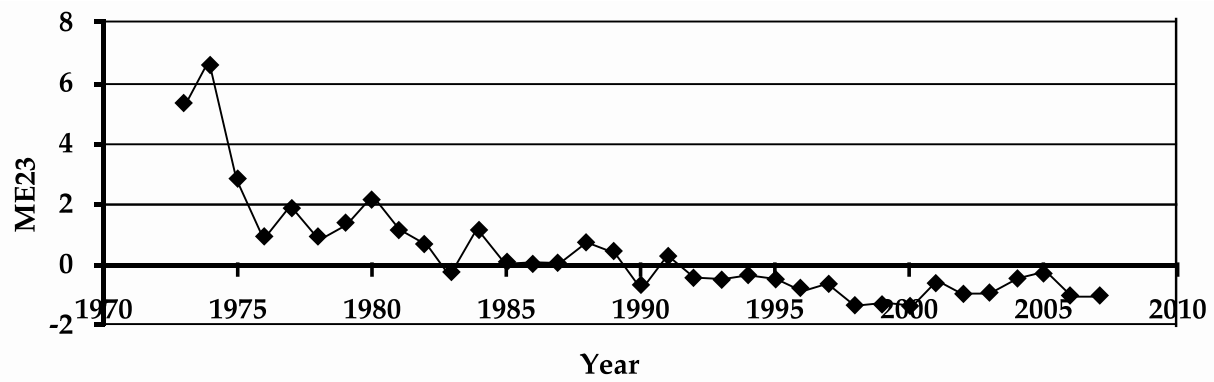

Figure 5: Morishima Elasticity ME31

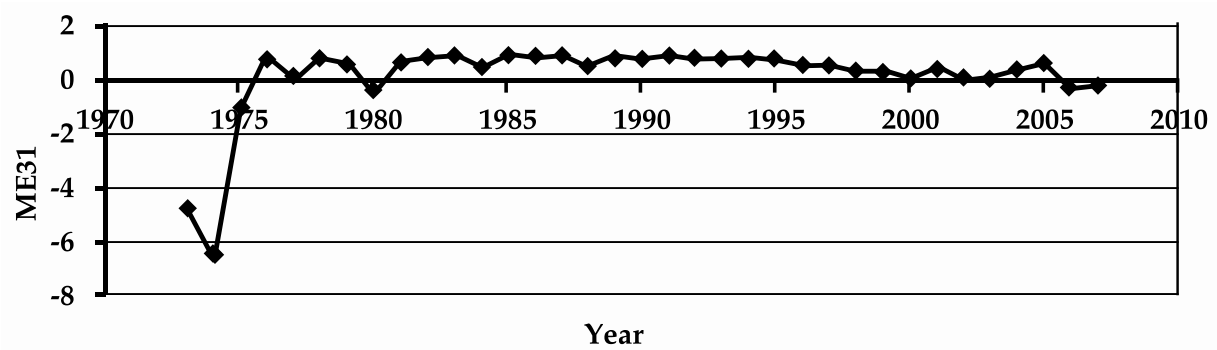

Table 6 shows that, in most years, the first three elasticities- $\mathrm{ME}_{12}$, $\mathrm{ME}_{21}$, and $\mathrm{ME}_{13}$-indicate substitution that is greater than unity. This finding is due mainly to the fact that the first subgroup includes the most liquid assets and the second includes demand deposits; with the development of the financial sector in Pakistan and smaller user cost of demand deposits, these two subgroups emerge as substitutes.

The results for the last three elasticities- $\mathrm{ME}_{23}, \mathrm{ME}_{13}$, and $\mathrm{ME}_{32}-$ are smaller than unity. The less-than-perfect substitution of these monetary assets indicates that we cannot treat them as equivalents, and so a simple summation of these assets to form monetary aggregates 
would be misleading. It also indicates that weighted aggregates are a better option for monetary aggregation. This result supports our main hypothesis that all monetary assets are not perfect substitutes for one another, as simple-sum aggregation might otherwise imply.

The results for both Allen and Morishima elasticities of substitution, when calculated at mean, augment our previous findings (see Table 7). According to Blackorby and Russell (1981, 1989), Allen elasticity is biased toward showing assets as complements. This is also evident from the table where, except for $\mathrm{AE}_{12}$, all the elasticities show the assets to be Allen complements.

Table 7: Allen and Morishima Elasticities at Mean

\begin{tabular}{lccc}
\hline Allen Elasticity & Morishima Elasticity & Allen Elasticity & Morishima Elasticity \\
\hline $\mathrm{AE}_{11}$ & -0.266 & $\mathrm{AE}_{11}$ & -0.266 \\
$\mathrm{AE}_{22}$ & -1.162 & $\mathrm{AE}_{22}$ & -1.162 \\
$\mathrm{AE}_{33}$ & -0.824 & $\mathrm{AE}_{33}$ & -0.824 \\
$\mathrm{AE}_{12}$ & 2.374 & $\mathrm{AE}_{12}$ & 2.374 \\
$\mathrm{AE}_{32}$ & -2.045 & $\mathrm{AE}_{32}$ & -2.045 \\
\hline
\end{tabular}

Source: Authors' calculations.

\section{Conclusion and Recommendations}

Our estimates of both Allen and Morishima elasticities corroborate previous findings in the literature, and strengthen the argument in favor of less-than-perfect substitution among monetary assets. On the basis of our results, we can conclude that simple-sum aggregates are inferior and do not have a strong theoretical base, while Divisia aggregates, which assume less-than-perfect substitution, provide more information content for policy formulation. Moreover, the variability in the elasticity of substitution is an indication of the stability of any nonlinear function.

The study's results show that the elasticity of substitution in the nonlinear AIM varies considerably. Thus, the money demand model is stable and monetary authorities should target the broad money aggregate. The consistent failure to handle inflation and money supply issues can be avoided by improving the monetary aggregation technique that is used. This transition from simple-sum to Divisia aggregation has been successful in many developed countries, and Pakistan, too, needs to switch to improved techniques given that its policies that are based on inferior aggregates have not proved successful. 


\section{References}

Akhtar, H. (1994). The search for a stable money demand function for Pakistan: An application of the method of cointegration. Paper presented at the $10^{\text {th }}$ annual general meeting of the Pakistan Society of Development Economists, Islamabad.

Banks, J., Blundell, R., \& Lewbel, A. (1997). Quadratic Engel curves and consumer demand. Review of Economics and Statistics, 79, 527-539.

Barnett, W. A. (1978). The user cost of money. Economics Letters, 1, 145-149.

Barnett, W. A. (1980). Economic monetary aggregates: An application of aggregation and index number theory. Journal of Econometrics, 14, $11-48$.

Barnett, W. A. (1983a). New indices of money supply and the flexible Laurent demand system. Journal of Business and Economic Statistics, $1,7-23$.

Barnett, W. A. (1983b). Definitions of second-order approximation and of flexible functional form. Economics Letters, 12, 31-35.

Barnett, W. A. (1985). The Minflex-Laurent translog flexible functional form. Journal of Econometrics, 30, 33-44.

Barnett, W. A., \& Jonas, A. (1983). The Müntz-Szátz demand system: An application of a globally well behaved series expansion. Economics Letters, 11, 337-342.

Barnett, W. A., \& Lee, Y. W. (1985). The global properties of the MinflexLaurent, generalized Leontief, and translog flexible functional forms. Econometrica, 53, 1421-1437.

Barnett, W. A., Geweke, J., \& Wolfe, M. D. (1991). Semi-nonparametric Bayesian estimation of the asymptotically ideal production model. Journal of Econometrics, 49, 5-50.

Barnett, W. A., Lee, Y. W., \& Wolfe, M. D. (1985). The three-dimensional global properties of the Minflex-Laurent, generalized Leontief, and translog flexible functional forms. Journal of Econometrics, 30, 3-31. 
Barnett, W.A., Lee, Y.W., \& Wolfe, M. D. (1987). The global properties of the two Minflex-Laurent flexible functional forms. Journal of Econometrics, 36, 281-298.

Barnett, W. A., \& Yue, P. (1988). Semi-nonparametric estimation of the asymptotically ideal model: The AIM demand system. In G. F. Rhodes \& T. B. Fomby (Eds.), Nonparametric and robust inference, Advances in Econometrics (7, 229-251). Greenwich, CT: JAI Press.

Blackorby, C., \& Russell, R.R. (1981). The Morishima elasticity of substitution, symmetry, constancy, separability, and its relationship to the Hicks and Allen elasticities. Review of Economic Studies, 48, 147-158.

Blackorby, C., \& Russell, R. R. (1989). Will the real elasticity of substitution please stand up? American Economic Review, 79, 882-888.

Chetty, V.K. (1969). On measuring the nearness of near-moneys. American Economic Review, 59, 270-281.

Cooper, R.J., \& McLaren, K.R. (1996). A system of demand equations satisfying effectively global regularity conditions. Review of Economics and Statistics, 78, 359-364.

Drake, L., \& Fleissig, A.R. (2004). Semi-nonparametric estimates of currency substitution: The demand for sterling in Europe. Review of International Economics, 12, 374-394.

Drake, L., Fleissig, A.R., \& Swofford, J. L. (2003). A semi-nonparametric approach to the demand for UK monetary assets. Economica, 70, 99-120.

Fisher, D., \& Fleissig, A.R. (1997). Monetary aggregation and the demand for assets. Journal of Money, Credit, and Banking, 29, 458-475.

Fisher, D., Fleissig, A.R., \& Serletis, A. (2001). An empirical comparison of flexible demand system functional forms. Journal of Applied Econometrics, 16, 59-80.

Fleissig, A.R., \& Serletis, A. (2002). Semi-nonparametric estimates of substitution for Canadian monetary assets. Canadian Journal of Economics, 35, 78-91. 
Fleissig, A.R., \& Swofford, J.L. (1996). A dynamic asymptotically ideal model of money demand. Journal of Monetary Economics, 37, 371380 .

Fleissig, A.R., \& Swofford, J L. (1997). Dynamic asymptotically ideal models and finite approximation. Journal of Business and Economic Statistics, 15, 482-492.

Gallant, A. R. (1981). On the bias in flexible functional forms and an essentially unbiased form: The Fourier flexible form. Journal of Econometrics, 15, 211-245.

Guilkey, D. K., \& Lovell, C. A. K. (1980). On the flexibility of the translog approximation. International Economic Review, 21, 137-147.

Havenner, A., \& Saha, A. (1999). Globally flexible asymptotically ideal models. American Journal of Agricultural Economics, 81, 703-710.

Khan, A. H. (1994). Financial liberalization and the demand for money in Pakistan. Paper presented at the $10^{\text {th }}$ annual general meeting of the Pakistan Society of Development Economists, Islamabad.

Offenbacher, E. K. (1979). The substitution of monetary assets. (Doctoral dissertation, University of Chicago, IL).

Serletis, A. (2007). The demand for money: Theoretical and empirical approaches (2nd ed.). New York, NY: Springer.

Serletis, A., \& Shahmoradi, A. (2005). Semi-nonparametric estimates of the demand for money in the United States. Macroeconomic Dynamics, 9, 542-559.

Serletis, A., \& Shahmoradi, A. (2007). Flexible functional forms, curvature conditions, and the demand for assets. Macroeconomic Dynamics, 11(4), 455-486.

Tariq, S. M., \& Matthews, K. (1997). The demand for simple-sum and Divisia monetary aggregates for Pakistan: A cointegration approach. Pakistan Development Review, 36(3), 275-291.

Uzawa, H. (1962). Production functions with constant elasticities of substitution. Review of Economic Studies, 29, 291-299.

Yue, P. (1999). A microeconomic approach to estimating money demand: The asymptotically ideal model. St. Louis, MO: Federal Reserve Bank of St. Louis. 